\title{
LA FUNCIÓN COHESIVA DE LA EXPRESIÓN TEMPORAL EN LA GRAN CRÓNICA DE ALFONSO XI
}

Elena Leal Abad

\author{
E.N.S. Editions | « Cahiers d'études hispaniques médiévales »
}

2013/1 n 36 | pages 259 à 284

ISSN $1779-4684$

ISBN 9782847885415

Article disponible en ligne à l'adresse :

http://www.cairn.info/revue-cahiers-d-etudes-hispaniques-medievales-2013-1-page-259.htm

\section{!Pour citer cet article :}

Elena Leal Abad, «La función cohesiva de la expresión temporal en La gran crónica de Alfonso XI », Cahiers d'études hispaniques médiévales 2013/1 (n 36), p. 259-284.

Distribution électronique Cairn.info pour E.N.S. Editions.

(c) E.N.S. Editions. Tous droits réservés pour tous pays.

La reproduction ou représentation de cet article, notamment par photocopie, n'est autorisée que dans les limites des conditions générales d'utilisation du site ou, le cas échéant, des conditions générales de la licence souscrite par votre établissement. Toute autre reproduction ou représentation, en tout ou partie, sous quelque forme et de quelque manière que ce soit, est interdite sauf accord préalable et écrit de l'éditeur, en dehors des cas prévus par la législation en vigueur en France. Il est précisé que son stockage dans une base de données est également interdit. 


\title{
La función cohesiva de la expresión temporal en La gran crónica de Alfonso XI
}

\author{
Elena LEAL ABAD
}

Universidad de Sevilla*

\begin{abstract}
RESUMEN
En la línea de la historicidad de los productos discursivos, el trabajo que se presenta trata de establecer una filiación textual entre el género informativo moderno y el cronístico a partir del análisis de las diferentes necesidades de estructuración de la materia informativa. Así, en las páginas que siguen se analizan los procedimientos de organización de la información entre los diferentes enunciados de los tres primeros libros de la Gran Crónica de Alfonso $X I$ con el objetivo de tratar de establecer tendencias de ordenación de la frase que supongan continuidad, desvío, reformulación o ruptura de la anterior tradición cronística alfonsí. Para ello, se analizan las expresiones que con mayor frecuencia ocupan la posición inicial, con el objetivo de rastrear patrones de progresión temática cuya coherencia se fundamente en el equilibrio entre la información presentada y la información nueva que se va introduciendo.
\end{abstract}

Palabras clave: tradición discursiva, coherencia, cohesión, tema, rema, discurso narrativo, discurso informativo, temporalidad

RÉSUMÉ

Cet article essaie d'établir une filiation textuelle entre le genre informatif moderne et les chroniques médiévales à partir des différentes formes d'organisation de la matière informative (solutions trouvées pour faire face aux besoins de structuration de la matière informative). Ainsi, dans les pages qui suivent, sont analysés les procédés d'organisation de l'information

* Este trabajo se inserta dentro del proyecto «Orígenes de la configuración histórica del discurso informativo en español: de la crónica medieval a la crónica de Indias», desarrollado en la UFR d'Études ibériques et latino-américaines de l'université Paris-Sorbonne durante la estancia de investigación de la autora en dicha institución entre el 1 de marzo y el 30 de abril de 2013. 
dans les trois premiers livres de la Grande Chronique d'Alphonse XI. Le but est de tenter d'identifier des tendances de l'ordre des mots dans la phrase et leur rapport de continuité, détournement, modification ou rupture vis-à-vis de la tradition historiographique précédente d'Alphonse X. Pour cela, sont étudiées les expressions qui occupent le plus fréquemment la position initiale, afin de repérer des patrons de progression thématique dont la cohérence obéirait à l'équilibre entre l'information présente et l'information nouvelle qu'on introduit.

Mots clés: tradition discursive, cohérence, cohésion, information donnée, information nouvelle, discours narratif, discours informatif, temporalité

De acuerdo a los postulados de la reciente Romanística alemana, propuestos a partir de las ideas emanadas de Coseriu y aplicados con éxito en los trabajos de Brigitte Schlieben-Lange ${ }^{1}$, Peter Koch ${ }^{2}$ y Wulf Oesterreicher $^{3}$, una lengua se realiza siempre imbricada en una tradición discursiva, por tanto, además de la historicidad de los sistemas lingüísticos hay otra historicidad, la de los productos discursivos que combinan en diferentes proporciones repetición y creatividad y hace que los enunciados sean reconocidos como pertenecientes a una determinada tipología textual ${ }^{4}$. Desde esta perspectiva, se ha ido perfilando en los últimos años una línea de investigación que trata de analizar la conformación histórica del discurso informativo en el ámbito de los estudios sintácticos orientados discursivamente. Los comienzos titubeantes de este género textual suelen situarse a mediados del siglo XVII, momento en el que se estabiliza una tradición discursiva existente de alguna manera ya en los dos siglos precedentes en los que, si bien no puede todavía hablarse de textos pre-periodísticos en sentido estricto, sí puede decirse que empieza a conformarse un tipo de tradición de carácter informativo con un objetivo público materializado en folletos breves, conocidos en la historia de la literatura mediante nombres diversos: Relaciones, Ocasionales, Avisos ${ }^{5}$. Esta última documentación

1. Brigitte Schlieben-Lange, Traditionen des Sprechens. Elemente einer pragmatischen Sprachgeschichtsschreibung, Stuttgart: Kohlhammer, 1983.

2. Peter Koch, «Diskurstraditionen: zu ihrem sprachtheoretischen Status und ihrer Dynamik», in: Barbara Frank, Thomas HaYe y Doris Tophinke (ed.), Gattungen mittelalterlicher Schriftlichkeit, Tübingen: Narr (= ScriptOralia, 99), 1997, p. 43-79.

3. Wulf Oesterreicher, «Zur Fundierung von Diskurstraditionen», in: Barbara Frank, Thomas Haye y Doris TopHINke (ed.), op. cit., p. 19-41.

4. El concepto de tradición discursiva es cada vez más frecuente en los estudios sobre las lenguas, especialmente en los de orientación diacrónica. Vid. Johannes KABATEK, «¿Cómo investigar las tradiciones discursivas medievales? El ejemplo de los textos jurídicos castellanos», in: Daniel Jасов у J. Kаватек (ed.), Lengua medieval y tradiciones discursivas en la Península Ibérica, Frankfurt/Madrid: Vervuert/Iberoamericana, 2001, p. 97-132. Id., «Tradiciones discursivas y cambio lingüístico», Lexis, 29 (2), 2005, p. 151-177. Id., «Las tradiciones discursivas entre conservación e innovación», Rivista di Letterature Ispaniche, 10, 2007, p. 331-348.

5. Tradicionalmente, estos textos han quedado al margen de los estudios lingǘsticos y, casi también, de los literarios, pues se tenían por obras «menores» situadas al margen de las tradi- 
ha constituido tradicionalmente el punto de arranque de la investigación sobre la evolución histórica del discurso informativo moderno a partir del análisis de estructuras inherentes desde los orígenes al oficio de informar tales como las referencias a las fuentes o a los mecanismos textuales de organización de la materia discursiva ${ }^{6}$.

El trabajo que se presenta forma parte de un ambicioso proyecto que trata de establecer una filiación textual entre el género informativo moderno y el cronístico a partir del análisis de las diferentes necesidades de estructuración de la materia informativa en el proceso de elaboración intensiva y extensiva del castellano comenzado con Alfonso X. A pesar de que en ambos casos se trata de discurso narrativo con una intención informativa, en el sentido de hacer saber a alguien algo que ha pasado, no cabe duda de que existen importantes diferencias entre el género cronístico y el discurso informativo tal y como se entiende en la actualidad. Así, las crónicas carecen de carácter funcional y utilitario y no presentan periodicidad en el sentido de regularidad de publicación. Existe en ellas una clara voluntad de estilo motivada por el deseo de que la escritura preserve la memoria de los hechos y se configure un arte de historiar con una intención ejemplar para el futuro supeditado a los proyectos políticos de los diferentes señoríos $^{7}$. Es cierto que las crónicas informan de guerras, asedios, resoluciones, juicios, enlaces reales, etc. Pero también es igualmente cierto que la selección de los acontecimientos narrados no se guía por los parámetros que operan en el discurso informativo actual, es decir, novedad, relevancia,

ciones lingüísticas susceptibles de irradiar una norma de carácter ejemplar, y carentes de interés estilístico y retórico. Han sido los historiadores del periodismo quienes han llamado la atención sobre tales textos como antecedentes del periodismo moderno, si bien las investigaciones que emanan de este campo han prestado poca atención a los hechos lingüísticos.

6. Los trabajos que se citan a continuación muestran el creciente interés por analizar la conformación histórica del discurso informativo en español: Margarita BorReguero ZuLOAGA y Álvaro Octavio de Toledo y Huerta, «La organización informativa en los textos periodísticos del siglo XviII: el Diario Pinciano», Res Diachronicae, 3, 2004, p. 77-106. Id., «La crónica de sucesos (ss. XVII-XIX). Evolución y desarrollo de la organización informativa textual», in: José Jesús Bustos Tovar y José Luis Girón Alconchel (ed.), Actas del VI Congreso Internacional de Historia de la Lengua Española, Madrid: Arco Libros, 3, 2006, p. 2653-2667; Id., «Presencia y función de los encapsuladores en las crónicas periodísticas del siglo XVII», Philologia Hispalensis, 21, 2007, p. 125-159; Elena LEAL ABAD, «La expresión de lo ponderativo en el discurso preperiodístico. Presencia y función de las oraciones consecutivas de intensidad en la información sobre catástrofes naturales», Revista de Historia de la Lengua Española, 6, 2011, p. 61-86; Elena LEAL Abad y Elena Méndez García de Paredes, «Aspectos lingǘsticos propios del discurso preperiodístico en las relaciones sobre el terremoto de Lisboa de 1755», Cuadernos Dieciochistas, 13, 2012, p. 75-109; Elena Méndez García de Paredes, «En los comienzos del discurso informativo: los Avisos de José Pellicer de Tovar (1639-1644)», in: Concepción Company y José G. Moreno DE Alba (ed.), Actas del VII Congreso Internacional de Historia de la Lengua Española, Madrid: Arco Libros, 2, 2008, p. 1949-1968.

7. Georges Martin (ed.), La historia alfonsi: el modelo y sus destinos (siglos XIII al XV), Madrid: Casa de Velázquez (Colección de la Casa de Velázquez, 68), 2000. 
actualidad, desviación o negatividad y $\operatorname{proximidad}^{8}$. Así, según señala Martin $^{9}$ para la Estoria de España, la territorialidad de la materia histórica y el neogoticismo son los criterios constituyentes en el enfoque del pasado.

A pesar de las diferencias señaladas y en la línea de la historicidad de los productos discursivos, resulta conveniente, con el fin de tener una visión más completa del proceso de conformación histórica del género informativo, retrotraerse a tradiciones discursivas anteriores que presenten, al menos incipientemente, patrones de comportamientos discursivos vinculados a la narración de acontecimientos necesarios en la organización informativa de los textos. Dentro de la disposición ordenada de la materia, la coherencia es un principio de textualidad que hace que las diferentes secuencias del texto sean accesibles entre sí y que las informaciones que se transmiten sean pertinentes o relevantes unas para las otras. Esta coherencia se manifiesta en la cohesión del discurso, es decir, en los mecanismos de trabazón que se establecen entre los segmentos del enunciado para configurar propiamente un texto ${ }^{10}$.

\section{La función cohesiva de la posición inicial}

En las páginas que siguen se analizan los procedimientos de organización de la información entre los diferentes enunciados de los tres primeros libros de la Gran Crónica de Alfonso XI ${ }^{11}$ [GCA] con el objetivo de tratar de establecer tendencias de ordenación de la frase que supongan continuidad, desvío, reformulación o ruptura de la anterior tradición cronística alfonsí, ampliamente estudiada en este sentido ${ }^{12}$. Para ello, se analizan las expre-

8. Parámetros establecidos para el discurso informativo actual por Teun A. VAN DiJk, La noticia como discurso. Comprensión, estructura y producción de la información, Barcelona: Paidós Comunicación, 1990, p.173-181.

9. G. Martin, «El modelo historiográfico alfonsí y sus antecedentes», in: G. Martin (ed.), op. cit., p. 23-24.

10. Dentro del análisis textual, la cohesión del discurso es uno de los fenómenos que más ha llamado la atención de los historiadores de la lengua. Vid. José Luis GIRÓn Alconchel, «Evolución de la cohesión en el discurso ensayístico entre 1648 y 1726», in: J. L. GiRón AlconcheL et al. (ed.), Estudios ofrecidos al profesor Fosé Jesús de Bustos Tovar, Madrid: Editorial Complutense, 1, 2003, p. 331-360.

11. El libro primero, que abarca la minoría de edad del rey (1312-1325), incluye la primera tutoría (1312-1319) y la segunda tutoría (1319-1325). El libro segundo se centra en la etapa de adolescencia del monarca a merced de los privados (1325-1328). El tercero abarca los años de paz y consolidación del reinado entre 1328 y 1332. Los tres libros aparecen recogidos en el primer volumen de la Gran crónica de Alfonso XI editada por Diego Gatalán, Madrid: Gredos, 1976.

12. Vid. Javier Elvira González, «La función cohesiva de la posición inicial de frase en la prosa alfonsí», Cahiers de linguistique hispanique médiévale, 18-19, 1993, p. 243-278. Id., «La organización del párrafo alfonsí», Cahiers de linguistique hispanique médiévale, 21, 1996, p. 325-342. Mercedes SuÁrez Fernández, «Las construcciones absolutas en el castellano primitivo. Su estructura interna», in: Alegría Alonso González (coord.), Actas del III Congreso Internacional de Historia de la Lengua Española, Salamanca: Arco Libros, 1, 1996, p. 583-596. Id., «Análisis de algunos paráme- 
siones que ocupan normalmente la posición inicial, entendida esta como los elementos antepuestos al verbo de la cláusula principal, con el objetivo de rastrear patrones de progresión temática cuya coherencia se fundamente en el equilibrio entre la información presentada y la información nueva que se va introduciendo. En este sentido, la prosa alfonsí se configuraba ya como ejemplo característico de discurso narrativo en el que la disposición lineal de los elementos informativos se articulaba en función de la coherencia del texto ${ }^{13}$.

El orden de palabras constituye un tema de interés tanto para el estudio de la lengua moderna como para la medieval. Para ambos períodos se han analizado los factores sintácticos y discursivos que condicionan las diferentes secuencias constructivas. El trabajo que se presenta se centra en estos últimos y parte de la premisa de que la posición inicial, que constituye el punto de arranque a partir del cual el productor textual hace avanzar su discurso, se reserva habitualmente para aquella información que se considera más accesible, en el sentido de que ya ha sido previamente proporcionada en el texto o se infiere fácilmente del contexto comunicativo. La Gran crónica, según se pondrá de manifiesto posteriormente, no constituye una excepción en este modo de organizar la información. En un intento de cuantificar las expresiones que habitualmente ocupan la posición inicial, hemos efectuado un recuento parcial que permite establecer un contraste ${ }^{14}$ :

tros implicados en la posición del sujeto en la cláusula intransitiva en textos del siglo xIII», in: J. L. Girón Alconchel y J.J. de Bustos Tovar (coord.), Actas del VI Congreso Internacional de Historia de la Lengua española, Madrid: Arco Libros, 2, 2006, p. 1153-1168. Id., «El tema y las funciones sintácticas en la lengua medieval», Verba: Anuario galego de filoloxia, 34, 2007, p. 157-200. Id., «Sobre el orden de constituyentes en la lengua medieval: la posición del sujeto y el orden básico en el castellano alfonsí», Cahiers de linguistique hispanique médiévale, 31, 2008, p. 263-310.

13. Vid. J. Elvira González, art. cit.

14. Hay que señalar el uso reiterativo de la conjunción $e$, procedimiento elemental de enlace oracional cuya presencia no desaparece ni en el caso de demostrativos iniciales, que sirven por sí mismos para conectar con el contexto. A diferencia de lo que ocurre en la Primera Crónica General, la conjunción copulativa $e$ aparece, aunque no con excesiva frecuencia, en la Gran Crónica en comienzo absoluto de capítulo. Para esta cuestión en textos de los siglos XIII y XIV, puede consultarse Francisco Javier Herrero RuIz De LoIzaga, «Organización del discurso en textos históricos de los siglos XIII y XIV: capítulos, apartados y sus formas de introducción», RILCE, 24 (2), 2008, p. 338-356, p. 339. 
Tabla $^{15}$

\begin{tabular}{|c|c|}
\hline TIPO DE EXPRESIÓN & GCA \\
\hline Sintagmas nominales & 71 \\
\hline Sujeto & 63 \\
\hline $\mathrm{CD}$ & 5 \\
\hline CI & 3 \\
\hline Sintagmas preposicionales ${ }^{16}$ & 13 \\
\hline Verbos & 29 \\
\hline Subordinadas temporales & 40 \\
\hline Desque & 25 \\
\hline Quando & 7 \\
\hline Antes que & 2 \\
\hline Luego que & 1 \\
\hline Después que & 5 \\
\hline Locuciones temporales & 15 \\
\hline Adverbios & 23 \\
\hline Adverbiales de gerundio & 12 \\
\hline Subordinadas causales & 7 \\
\hline Subordinada concesiva & 5 \\
\hline Secuencias iniciales complejas & 40 \\
\hline
\end{tabular}

\section{Sintagmas nominales antepuestos}

Los datos observados nos permiten constatar que es la función sujeto la que con más frecuencia sirve de punto de partida del mensaje, al constituirse en elemento temático de la frase. Los sujetos que de manera prototípica ocupan la posición antepuesta al verbo se caracterizan por tener niveles altos de agentividad, animación y control y suelen presentarse como entidades activadas gracias a la presencia de un artículo, un demostrativo o un nombre propio al que no es necesario añadir información de carácter incidental a modo de aposición:

15. Los datos procedentes de la Gran Crónica de Alfonso XI corresponden a un recuento parcial efectuado en los capítulos I-X y L-LX ambos inclusive. Hemos operado considerando un enunciado como la secuencia textual separada por un punto independientemente de que este estuviera constituido por una oración o grupo oracional.

16. Se han eliminado de este grupo los sintagmas en función de complemento indirecto y aquellos que constituyen locuciones temporales. La heterogeneidad de criterios (sintácticos, morfológicos y semánticos) manejados en la tabla se justifica por el deseo de claridad en la exposición de los resultados. 
E el arçobispo fuese para Castro Nuño (GCA, XXV, 11). Este rrey de Granada dexo dos hijos e vna hija (GCA, LXVIII, 3). E Ozmin ovo fabla con aquel Mahomad primo del rrey, e con su hermano (GCA, LXX, 23).

No obstante, el texto ofrece casos en los que el sujeto en posición inicial no necesariamente se corresponde con información dada sino que la situación preverbal se constituye en mecanismo discursivo para lograr fines comunicativos diversos. Así, es frecuente que la posición inicial del sujeto contribuya a señalar cambios alternativos de protagonismo de la acción. El paralelismo en el modo de actuar de los personajes puede llevar a no hacer explícito el verbo de la segunda oración, que se infiere fácilmente al coincidir con la primera, como sucede en el siguiente ejemplo:

E el ynfante don foan tornose para Dueñas; e el ynfante don Pedro para Valladolid (GCA, VII, 41).

En otros casos se repite la misma estructura predicativa en las cláusulas unidas por la sucesión o alternancia de sujetos:

E para esto el rrey de Castilla puso en rrehenes algunos castillos e alcaçares de su rreyno en poder de omes naturales del rreyno de Portogal; e otrosi el rey de Portogal puso castillos e alcaçares de su señorio en poder de omes naturales del rreyno de Castilla (GCA, XCV, 20-21). E el rrey, oyda esta respuesta que le enbio don Joan a decir, por dar comienço al fecho que viniese a bien, $[\ldots] \mathrm{E}$ don foan, oydas las rrazones que el rrey le enuiaua a decir, dixo que non queria verse con el en ninguna parte (GCA, XCVIII, 17-19).

O se utilizan verbos complementarios de carácter deíctico del tipo ir/venir:

Desque las bodas fueron fechas e los pleitos e posturas firmados, los rreyes se partieron muy amigos; e el rey de Castilla vino a Çibdad Rrodrigo, e con el la rreyna doña Maria su mujer, e la rreyna doña Beatriz de Portogal, e la infanta [...] e el rrey de Portogal fuese para su tierra (GCA, XCVI, 3-9).

El deseo de establecer un contraste entre los participantes es más evidente en aquellas secuencias que reproducen de forma indirecta ${ }^{17}$ discursos ajenos, en las que el hecho de asignar a cada entidad participante la posición más relevante de la secuencia permite el contraste de reacciones entre los interlocutores del intercambio comunicativo:

17. Son muy esporádicas las muestras de discurso directo: «E quando el rrey de Granada vio el mensaje del Ynfante ouo ende muy gran pesar, e dixo: Yo moro so, e el ynfante christiano; yo quiero guardar la verdat que Dios establesçio, e el aver que yo di al ynfante non lo quiero tomar, e el aver que yo di al Ynfante non lo quiero tomar, mas quiero guardar la carta de la fieldat que el me dio por esta rrazon [...], por que todos los del mundo sepan que es fe e verdad» (GCA, XIX, 13-20). «E ellos dixeronle: Señor, vos estades con vuestra honra, estad quedo, ca ellos no cunplen ninguna cosa de lo que dixeron; e fazemos vos jura e pleito e omenaje, que si ellos vinieren vn paso contra vos, que yremos diez pasos contra ellos» (GCA, XLI, 41-42). También hay secuencias dialogadas en estilo directo entre los personajes (GCA, XLII, 32-43). 
E don foan enbio luego su mandado al ynfante don Felipe a dezille que era venido alli para lidiar con el, e que saliese fuera, que el presto estaua para ello. E el ynfante don Felipe enbio le a decir que el fazia muy gran tuerto [...] (GCA, XXX, 4-6).

Muchos de estos parlamentos se articulan a través de una sintaxis compleja con un alto grado de incrustación sintáctica que verbaliza los razonamientos discursivos de los personajes a través de relaciones sintáctico-semánticas de causalidad, consecuencia, adversación, condición, concesión y finalidad. Es precisamente en estos entornos de discurso referido, en los que se paraliza la narración, en los que la posición inicial se reserva habitualmente para las relaciones de subordinación que dan cuenta de la complejidad en la articulación del pensamiento. Así, en el siguiente fragmento puede observarse en la primera intervención, atribuida a los infantes don Juan y don Juan Núñez, la constante ilación de las oraciones y, dentro de ellas, el deseo de reservar la posición temática dentro de las oraciones completivas a cláusulas subordinadas de gerundio con valor causal, condicional y adverbial causal:

E luego a pocos de días vinieronse para la rreyna doña Maria a Valladolid e fablaron con ella, e dixeron que conosçiendo quanto bien e quanta merçed les viniera della, especial mente en que / les diera los cuerpos d'anbos a dos por dos vezes e si non por ella que fueran muertos, e que ellos, rreconosçiendo todas estas cosas, que querían que fuera tutora del rrey don Alfonso su nieto, mas que no lo fuese el ynfante don Pedro su hijo, ca ellos no consintirian que el lo fuese en ninguna manera; e que si ella no tomase esta tutoria, que daría muy grande ocasión por do ouiese guerra e mal entrellos, e que toda la tierra se estragaría; e que le pedian por merçed, que pues ellos esto querían, que enbiase ella por el ynfante don Pedro e que le hiziese hazer esto. E ella les rrespondio que no queria esta carga desta tutoria por que era muy flaca, e que sabia muy bien quan grande peligro en ello auia; mas que ella enbiaria por el ynfante don Pedro, e que hablaria con el este fecho, e que punaria con el e con ellos de los asosegar a todos por que lo que se hiziese fuese con consejo e con acuerdo de todos, e si por ventura esto / no se pudiese hazer, que ante tomaria este afán por partir contienda entre ellos e no oviese daño en la tierra (GCA, I, 13-20).

Cabe señalar en estos contextos de reproducción la aparición de un procedimiento muy habitual, no solo en las crónicas, ampliamente documentado en la obra alfonsi $1^{18}$. Se trata del encuadramiento de una secuencia o constituyente entre la conjunción que introductora de cláusula completiva y la repetición de la misma conjunción al final del segmento que se enmarca en la posición inicial de dicha cláusula:

E [don Juan Nuñez] fuese luego para la rreyna doña Maria, e hablo con ella e contogelo todo, e dixo que si ella se lo mandase que yria alla. E la rreyna dixo

18. Vid. M. SuÁrez Fernández, «El tema y las funciones sintácticas...», p. 190. 
que este fecho era muy grande e muy peligroso e que era mucho de catar, e que pensaría sobrello e que ella diría lo que ay entendiese (GCA, II, 2-5).

A veces el análisis sintáctico de los pasajes que reproducen discursos ajenos no es sencillo. Es lo que sucede en el siguiente ejemplo, que muestra la reacción de los partidarios de los infantes don Juan y don Juan Núñez al recibir la noticia de la inminente llegada del infante don Pedro a las cortes de Palencia celebradas en 1313, que se traduce en una petición explícita a la reina doña María para que medie en el establecimiento de una tregua entre ambos bandos que facilite el entendimiento en las cortes:

E luego que supieron [ellos] que era movido para venir, dixeron que este ay/ untamiento non era bueno si non ouiese tregua entrellos, ca pues el ynfante don Pedro venia asonado e ellos otrosi estauan allí asonados, que no podia ser que non oviese pelea entrellos, [...] (GCA, IV, 12).

En este caso, dixeron introduce una completiva que forma parte, como apódosis, de una estructura condicional (con los tiempos típicos de las condicionales en discurso referido: imperfecto en la apódosis y - se en la prótasis). Tras la reproducción, $c a$ introduce una justificación, de la que podemos dudar si es justificación dada por el narrador o por los infantes. En cualquier caso, se trata de una justificación de enunciación, no de enunciado. Pero inmediatamente introduce un pues que es una causal antepuesta. De este modo ca queda solo, aislado, ¿cuál es su oración?, no parece haber. Lo que viene a continuación, "pues el ynfante...» parece tratarse de un discurso indirecto mimético, es decir, esa oración, con su pues, estaría en el discurso de los infantes don Juan y don Juan Núñez. Es la motivación antepuesta, solemne, consabida, que dan esos dos personajes para justificar que no puede sino haber pelea. Y a continuación, la oración encabezada por que remite nuevamente al dixeron, aunque se trata más bien de una subordinación discursiva que estrictamente sintáctica. Es decir, el que lo que hace es seguir recordando que continuamos estando ante un discurso reproducido (indirecto).

Constituye también un rasgo recurrente en las crónicas que los discursos reproducidos en forma indirecta, dependientes de algún verbo o elemento nominal que implique un acto lingüístico, se acumulen en largas tiradas que acaban reconociéndose como discurso referido fundamentalmente por la recurrencia de que, señal demarcativa de ese tipo de enunciado ${ }^{19}$. Esta repetición del nexo completivo dependiente del verbo de enunciación del

19. Rafael Cano Aguilar, «Aspectos discursivos en la historia de los períodos oracionales complejos en castellano medieval», in: Rosa María Castañer Martín y Vicente LagüÉns Gracia (ed.), De moneda nunca usada. Estudios filológicos dedicados a fosé $M .{ }^{a}$ Enguita Utrilla, Zaragoza: Institución Fernando el Católico, 2010, p. 149-162, p. 157. 
marco de la cita funciona como mecanismo ilativo. Además de este recurso, en el siguiente enunciado se observa dentro de las cláusulas subordinadas un encuadramiento de los sintagmas nominales criança y chançilleria, que ocupan la posición inicial y que quedan enmarcados por la repetición de la conjunción que. Este hecho constituye el resultado de la anteposición topical de estos dos nombres fuera de su oración subordinada:

Acordaron que cobrasen al rrey e que la su criança que la oviese la rreyna doña Maria su abuela e no otro ninguno; e que la chançilleria que estuviese con el rrey e que no vsasen de aquellos sellos que trayan e que los quebrantasen, e que tomasen cartas blancas (GCA, VII, 48-50).

La presencia de demostrativo en el sintagma nominal sujeto, con el fuerte poder conectivo de su función anafórica, no siempre contribuye a hacer avanzar el discurso. En ocasiones introduce información secundaria o accesoria con respecto al hilo narrativo principal. Este desvío hacia información tangencial constituye un recurso discursivo para situar a un personaje dentro de un determinado linaje, enumerar sus posesiones o añadir datos de su personalidad ${ }^{20}$ :

E el rrey mando poner acuçia por cobrar los castillos de la horden; e cobro los todos el maestre don Joan Nuñez, salvo el castillo de la villa de Çurita. E este don/Foan Nuñez fue hijo de la ynfante doña Blanca, señora de las Huelgas de Burgos, hija del rrey don Alonso de Portogal, hermana del rrey don Donys de Portugal (GCA, LV, 14-17). Y en este tiempo era en Aragon doña Blanca, hija del ynfante don Pedro de Castilla, con la infanta doña Maria su madre, hija del rrey don Jayme de Aragon; y esta doña Blanca avie en el rreyno de Castilla muchas villas e castillos e lugares muy fuertes (GCA, LVI, 9-10). E Garçi Laso partió del rrey en Cordoua para se yr do el rrey le avie mandado. E este Garçi Laso era ome que cataua mucho en agueros e traya omes que sabian mucho desto (GCA, LXXXIII, 29-30).

Asimismo, el empleo de los determinantes demostrativos este/aquel junto a nombres propios sirve para indicar respectivamente cercanía o lejanía textual de los referentes a los que acompañan:

En este tienpo rreinava en Granada Mahomat hijo de Ysmael, e era caudillo de la caualleria de Granada Ozmin. E aquel Mahomad rrey de Granada no salia del Alhambra, [...] E este Ozmin, desque supo quel rrey don Alonso [...] (GCA, CV, 2-10).

Aunque dentro de los sintagmas nominales la función de sujeto es la más

20. Se trata de enunciados descriptivos en los que se paraliza la narración de tipo fáctico característica de la crónica. En el estilo periodístico de todas las épocas esta función se reserva para las estructuras apositivas empleadas con el fin de identificar los nombres propios que se constituyen en noticia informativa. 
proclive a ocupar la posición inicial de la frase, es frecuente que un pronombre demostrativo neutro en función de OD, constituido en elemento anafórico, ocupe esta posición. Así, en los siguientes casos, el OD tematizado está desempeñado por un demostrativo que enlaza con la información presentada en el contexto precedente, de forma que el tema ejerce una función cohesiva de enlace textual. Estas expresiones resumen o sintetizan la entidad que ha constituido el asunto de la materia discursiva anterior, situada normalmente en una cláusula muy próxima. De todo ello dan cuenta los siguientes ejemplos:

E esto hizieron ellos por el pleyto que auian puesto con el ynfante don Juan e con don Juan Nuñez (GCA, III, 16). E esto hazie el teniendo que por la desavenencia destos farian a el tutor del rrey (GCA, III, 58). E todo esto hazie señalada mente don Juan Nuñez por que la rreyna se tenie con el ynfante don Pedro su hijo. (GCA, IV, 8). Y esto hizieron ellos por consejo del ynfante don Joan por que pusiera pleito e amorio (GCA, VIII, 30). Esto todo fazian ellos por tirar la tutoria al ynfante don Pedro (GCA, XII, 5). E todo esto fazia el rrey por lo asosegar en el su seruiçio en por le fazer honrra (GCA, LVI, 39).

Se trata de un patrón historiográfico ampliamente documentado en la prosa alfonsíi ${ }^{21}$ :

Y esto fizieron por muchas razones (PCG, 76a, 53-54). E tod esto fazie por sabor dauelle de la su part (PGG, 24a, 30).

Discursivamente, el empleo de un demostrativo neutro que se constituye en tema (inmediatamente antepuesto al verbo de la cláusula) de un enunciado constatativo y que sintetiza la acción narrativa anterior constituye un mecanismo de injerencia del narrador, que trata de justificar las acciones de los personajes, de ahí que casi todas las estructuras presenten el verbo fazer seguido de una expresión causal. El narrador, organizador de la textura discursiva, exhibe en la crónica un alto grado de conocimiento de los acontecimientos ${ }^{22}$, que son narrados casi en todo momento

21. Vid. M. Suárez Fernández, «El tema y las funciones sintácticas...», p. 168.

22. El cronista hace alusión al carácter de discurso ajeno de la información que transmite a través de menciones imprecisas que contrastan con la cuidadosa identificación de las fuentes en la prosa alfonsí (Vid. G. MARTIN, art. cit., p. 17) y que no pasarán al estilo informativo moderno: «E dizese que murieron en esta batalla bien mil e quinientos caballeros moros honrados de grande cuenta» (GCA, X, 47), «E esto fue por culpa del maestre, ca dizen que en el tienpo que los caualleros frayles estauan en el mayor afincamiento de la pelea con los moros, que fuyo el maestre (GCA, XLIV, 8), «E algunos dixeron que partieran el cuerpo de Dios e fizieran jura sobre la Cruz e los Santos Evangelios» (GCA, LIII, 14). La credibilidad de los hechos parece no ponerse en duda y, de hacerse, el narrador hace referencia a la historia como garantía de fidelidad a los hechos narrados: «segund quenta la ystoria» $(G C A, \mathrm{X}, 46)$, «Quenta la historia que el ynfante don Pedro entro otra vez en tierra de moros» (GCA, XI, 2), «Padre de este rrey don Alonso de quien habla esta Coronica» (GCA, XIII, 17), «Cuenta la estoria» (GCA,XVIII, 2), «E dize la ystoria 
en tercera persona en modo omnisciente. No obstante, la objetividad en el relato, que rara vez señala inequívocamente al responsable inmediato, no es absoluta. Oculto tras la tercera persona, el narrador no se limita a transmitir información sino que también valora e interpreta conductas ${ }^{23}$ y el molde de OD tematizado le sirve para establecer injerencias de tipo evaluativo y opinativo sobre entidades con un notable grado de activación dada por la proximidad de la última mención referencial en el texto. Cabe señalar que ninguno de los casos analizados de anteposición de OD tematizado presenta reduplicación pronominal. El hecho de que el pronombre demostrativo neutro sustituya a entidades fácilmente accesibles, parece ser una de las circunstancias que favorece la ausencia de clíticos ${ }^{24}$.

Mucho menos frecuente es la tematización del OI. En el corpus manejado se ha rastreado su presencia en la posición inicial de los períodos en muy pocas ocasiones. En todas ellas aparece la reduplicación pronominal del objeto nominal (tanto pronominal como nominal), caracterizado por el factor humano, indirecto y antepuesto:

E a ellos llegoles mandado otrosi de commo el ynfante don Pedro queria yr ay; (GCA, III, 19). E al ynfante don Pedro vinole grande enojo (GCA, III, 31). E al ynfante don Pedro llegole este mandado; (GCA, VIII, 19). E a don Foan Nuñez e a Sancho Sanchez de Velasco paresçioles que se non viese con ella, por que non querian que oviese ay concordia entrellos (GCA, IV, 35).

En la prosa alfonsí, la tematización del CI con clítico se producía cuando se daban las siguientes condiciones: el tema aparecía separado o aislado por una pausa más o menos fuerte ya sea por tratarse de una unidad que conlleva una entonación específica, ya sea por la presencia de un adverbio

que» (GCA, XX, 12), «E segund dize la historia» (GCA, XX, 27 y 29), «Dize la historia que» (GCA, XXXVIII, 4), «Segun se ffalla por las coronicas e estorias antiguas» (GCA, LXVI, 4).

23. El narrador da cuenta de su deseo de organizar la materia discursiva de forma ordenada: «E pues la ystoria a contado como ordeno el rrey su casa, agora contara como fablo con todos los que eran ajuntados con el allí por su llamamiento» $(G C A, \mathrm{LI}, 17)$. Normalmente se sigue un orden cronológico aunque no siempre. Hay casos en que determinados acontecimientos quedan en suspensión de un capítulo a otro. De esta manera, el narrador se hace presente para remitir internamente a información ya narrada o para anticipar parte de las secuencias que desarrollará más adelante: «Ella vendio estos dichos lugares como desuso es dicho» (GCA, VIII, 15), «Como la historia vos a ya contado» $(G C A, \mathrm{X}, 2)$, «Segund adelante oyredes a do fuere su lugan (GCA, XVIII, 8), «Ya oystes, segund vos conto la estoria» (GCA, XIX, 11), «Segund que la ystoria lo a contado» (GCA, XXIV, 17), «E de las otras cosas en como pasaron la ystoria las contara» (GCA, XXXIV, 27), «Quando los nauarros supieron la muerte de los infantes don Pedro e don Joan, que murieron en la Vega de Granada como de suso vos lo a contado ystoria» (GCA, XXXV, 2).

24. Este hecho fue constatado por Suárez para textos del siglo XIII: «El CD tematizado, cuando no va acompañado de clítico correferencial, está desempeñado frecuentemente por expresiones que contienen un demostrativo que enlaza con la información presentada en el contexto precedente de modo que el tema ejerce una función cohesiva, de enlace textual» (M. SuÁrez FERnández, «El tema y las funciones sintácticas...», p. 168). 
o de alguna función que se interpone entre el CI y el verbo ${ }^{25}$, ya sea por la distancia entre el tema y el predicado porque entre ambos se inserta información variada, ya sea por la extensión del segmento temático o por situar el tema fuera de la predicación. En tales circunstancias el valor del clítico consistía en articularse como elemento anafórico para retomar el referente que quedaba de algún modo aislado o un tanto desgajado de la predicación y de esa manera marcar su vinculación con el predicado ${ }^{26}$. No obstante, estas características sintácticas de carácter secuencial que explicaban la presencia de la reduplicación de clíticos como patrón historiográfico alfonsí no se cumplen en los ejemplos documentados del corpus analizado. En todos los casos se trata se entidades fácilmente accesibles por el contexto, en los que no media secuencias intercaladas y en las que tampoco se observa un deseo de marcar con la presencia del clítico la alternancia temática. En estos casos, pues, la finalidad del clítico no puede vincularse con el deseo de facilitar el seguimiento del referente temático de codificación dificultosa o de menor activación para integrarlo en el predicado. El hecho de que las condiciones de clítico repetitivo que había en Alfonso X ya no sean las que presenta la Gran Crónica, podría llevar a pensar en un progreso del proceso de gramaticalización ${ }^{27}$.

\section{El verbo como elemento inicial}

Todo texto narrativo establece una sucesión temporal de acciones en la que se ven implicados ciertos agentes a los que les suceden cosas. De ahí la importancia que adquieren los verbos en los relatos. Las acciones expresadas por ellos suelen constituir elementos que hacen avanzar la materia informativa, es decir, los verbos canalizan información no introducida previamente en el discurso sino añadida a él a modo de progreso informativo $^{28}$. Si se tiene en cuenta una disposición coherente de la materia,

25. Sobre el uso de la reduplicación de los pronombres personales átonos en textos medievales, vid. Timo Riıно, La redundancia pronominal en el iberorromance medieval, Tübingen: Niemeyer, 1988, p. 13-20.

26. M. SuÁrez Fernández, «El tema y las funciones sintácticas...», p. 182.

27. Para un análisis pormenorizado de la evolución histórica de este proceso desde los primeros textos, puede consultarse Joel RinI, «The redundant indirect object construction in Spanish. A new perspective», Romance Philology, 45 (2), 1991, p. 269-286.

28. Las actitudes discursivas de narrar, por un lado, y comentar u opinar, por otro, se manifiestan lingüísticamente en la selección de los tiempos verbales y de los elementos anafóricos de carácter temporal. En este sentido, tanto Émile Benveniste como Haral Weinrich, al observar que cierto tipo de formas verbales aparecen en unas situaciones comunicativas y no en otras, establecieron dos grupos diferenciados de tiempos verbales: tiempos de la historia y tiempos del discurso (Benveniste), y tiempos del mundo narrado y tiempos del mundo comentado (Weinrich). Así, pretérito simple, imperfecto, condicional y pluscuamperfecto, pertenecen al «mundo narrado» o a la historia; mientras que presente, antepresente o perfecto compuesto y futuro, pertenecen al «mundo comentado» o al discurso. 
cabe esperar que los sintagmas verbales no constituyan el arranque del mensaje sino que se sitúen más bien en una posición central dentro de la cláusula predicativa. Esta es precisamente la tendencia más habitual que se observa en el corpus analizado. El verbo inicial aparece en fórmulas de encuadre de la materia informativa del tipo cuenta la estoria (GCA, XI: 2 y XVIII, 2) o las variantes contado a la ystoria (GCA, XLI, 3) y dize la ystoria (GCA, XLIV, 5). Estas fórmulas presentan de forma abrumadora el sujeto pospuesto. El rechazo a la posición inicial tal vez pueda explicarse por el hecho de tratarse de predicaciones con sujeto no agentivo desde la perspectiva semántica. En otras palabras, en estos casos la entidad sujeto no ejecuta o desencadena un proceso. No es una entidad responsable humana o animada sino que el proceso se realiza en ella.

El verbo también ocupa la posición inicial en los casos en los que se materializa la figura del narrador para disponer la materia discursiva, con una función muy similar a los ejemplos anteriores:

Dicho auemos en como el rrey don Alfonso dio el adelantamiento de la frontera a don Joan fijo del Ynfante don Manuel (GGA, LVIII, 2). Dicho auemos como el rrey estaua en Burgos (GCA, LXI, 2).

Salvo en estas circunstancias de carácter formulario, la posición inicial de los verbos no es la más habitual. Esto no quiere decir que tal disposición sea completamente desconocida:

E mouieron luego pleito que la rreyna que saliese de Palençia, (GCA, IV, 22). E enviaron luego a demandar rrehenes a la rreyna y a los infantes don Joan y don Pedro tutores (GCA, XII, 6). Dexo el pleito asi asosegado, e fuese para Segouia (GCA, XXXII, 10). E pasaron asi aquella noche (GCA, LX, 5). E dio a Aluar Nuñez a Belver por eredad (GCA, LXII, 4).

Se suele afirmar que la prosa medieval española, especialmente la de carácter historiográfico, muestra una tendencia a construir frases con verbo inicial para lograr el efecto de aumentar el ritmo narrativo. En los textos históricos alfonsíes esta ordenación se documenta con todos los tiempos verbales, aunque con predomino del indefinido ${ }^{29}$. A pesar de que la casuística de las frases con verbo inicial es muy variada en los textos medievales, en la crónica analizada parecen existir dos circunstancias que favorecen la anteposición de los verbos en indefinido. En primer lugar, la no presencia de un sujeto explícito; en segundo lugar, la existencia de adverbios de modo (así) o de tiempo (luego) en una posición muy cercana. Ambos factores contribuyen a la cohesión verbal. En el primer caso, la elipsis del sujeto hace depender el verbo de un agente plenamente activado en

29. Vid. J. Eluvira González, art. cit., p. 252. 
la secuencia inmediatamente anterior; en el segundo caso, la presencia de adverbios de tiempo introduce una información que necesita la referencia de la secuencia anterior para orientarse y, finalmente, el adverbio asi sintetiza las circunstancias modales previamente introducidas. De esta manera, la aparición del verbo en posición inicial no se encuadra desgajada de la información precedente. Todo lo contrario, los indefinidos aparecen arropados por mecanismos de cohesión que los anclan inevitablemente en el discurso previo.

\section{Sintagmas preposicionales antepuestos}

Los sintagmas preposicionales pueden preceder al verbo en determinadas circunstancias discursivas y ocupar la posición inicial. Dejando al margen los pocos casos de CI tematizado y las locuciones temporales del tipo en este año utilizadas a menudo para iniciar los capítulos, los sintagmas preposicionales que se anteponen al verbo aparecen normalmente después de la intercalación en el relato de un fragmento de discurso reproducido. Tras estos incisos en los que se reproduce el discurso ajeno de forma indirecta y con alternancia de interlocutores, es habitual que la narración se reinicie con un sintagma que condensa y remite anafóricamente al fragmento anterior:

E con esta respuesta fuese luego de Valladolid el ynfante don Juan, e don Juan Nuñez de la barba, que era señor de Lara, quedo en Valladolid [...] (GGA, I, 21-22). E con este acuerdo se fue don Juan Nuñez para Avila, e la rreyna enbio su mandadero adelante a don Sancho, [...] (GCA, II, 13-14).

Estas construcciones nominales de condensación informativa y de carácter anafórico que simultáneamente funcionan a modo de síntesis de la información previamente presentada y de punto de arranque para la introducción de nuevos contenidos reciben el nombre de encapsuladores ${ }^{30}$ y están atestiguadas desde los comienzos de los géneros pre-periodísticos. Se trata de expresiones que sintetizan el tipo de acto de habla acometido previamente. En ningún caso en el corpus analizado se valoran a través de estos sintagmas los acontecimientos que se condensan ${ }^{31}$. De hecho, es muy habitual que con esta función aparezcan sustantivos de significado muy general y de carácter neutro. Asimismo, es frecuente que la expresión nominal vaya precedida de un demostrativo que refuerza el carácter cohesivo:

30. Vid. M. Borreguero Zuloaga y Á. Octavio de Toledo y Huerta, art. cit.

31. Los textos informativos a partir del siglo XVII irán desarrollando elementos anafóricos de condensación informativa de significado más conciso y en los que se valoran los acontecimientos que se condensan. Vid. ibid., p. 148. 
E por todas estas rrazones acordó que don Juan Nuñez que fuese e lo non tardase a Avila, e que guisase que el rrey non lo sacasen de Avila [...] (GCA, II, 11-12). $\mathrm{E}$ con este rrecabdo se tornaron los mensajeros e contaron la respuesta del rrey de Granada al ynfante don Pedro (GCA, XIX, 21). E por esta rrazon acordaron todos de enviar por el ynfante don Felipe que fuese para ellos (GCA, XXXIII, 6).

En algunos casos el sustantivo seleccionado no es más que la forma nominal derivada del verbo principal del acontecimiento narrado:

[...], rresçibieron al rrey con gran placer e con grandes alegrías. E en este rresçebimiento ovo muchas danças de omes e de mugeres (GCA, LXV, 11-12). E salieron/lo a rresçebir fuera de la çibdad. E el rresçebimiento del rrey fue con muy grand plazer (GCA, LXV, 24-25).

Además de la presencia nada despreciable de sintagmas nominales plenos en estas estructuras, el narrador recurre al empleo de deícticos metatextuales que se refieren anafóricamente a los acontecimientos descritos:

E desto avie el muy gran pesar (GCA, LVII, 6). E por esto avia enbiado alla a este don Joan por adelantado (GCA, LVIII, 2).

\section{La complejidad sintáctica de la posición inicial}

En los discursos de la inmediatez comunicativa no es habitual que la posición preverbal se articule con un alto grado de complejidad estructural. Esta forma de organización parece más propia de textos de la distancia en los que la planificación previa y el hecho de que habitualmente se transmitan por el soporte escrito facilitan la decodificación del mensaje por parte del receptor. Discursivamente, la complejidad sintáctica de la posición inicial puede constituirse en un mecanismo con el que se logran tres objetivos: (1) dibujar el escenario en el sentido de facilitar una información previa necesaria para situar referencialmente (tiempo, lugar) los acontecimientos narrados u orientar la interpretación de la oración principal (relaciones de causalidad, condición, finalidad), (2) precisar explícitamente las circunstancias de razonamiento lógico que enmarcan la predicación de la nueva cláusula y (3) acrecentar el interés informativo respecto a un elemento activado o fácilmente accesible ${ }^{32}$.

En el corpus analizado se observa que con relativa frecuencia la posición antepuesta al verbo está ocupada por una o más construcciones sintácticas de diferente grado de complejidad que habitualmente aportan un

32. La presentación de un referente del que se espera que se diga algo y cuyo comentario se demora mantiene la expectativa. Se trata de una estructura que contribuye a mantener el referente activo, especialmente cuando además es participante de las cláusulas que se insertan entre él y la predicación. Vid. M. SuÁrez Fernández, «El tema y las funciones sintácticas...», p. 164. 
contenido de carácter circunstancial (frases adverbiales, expresiones de finalidad, condición, etc.) a la predicación principal. Estas oraciones, que ocupan la posición temática, sirven de engarce textual con la materia anteriormente introducida y, simultáneamente, funcionan como elementos de transición hacia unidades de contenido informativo nuevo. El discurso se organiza, pues, a modo de encadenamientos en los que los elementos circunstanciales de la información previa sirven para enmarcar las circunstancias de la nueva enunciación.

Dentro de las técnicas de cohesión discursiva, la subordinación antepuesta (finales, temporales, condicionales, causales) suele, debido a su carácter frecuentemente temático, servir de tránsito entre unidades de mayor contenido comunicativo añadiendo información secundaria que permite enmarcar la nueva acción dentro de unas coordenadas circunstanciales que sitúan la predicación principal. El hecho de anteponer las circunstancias que enmarcan la predicación, sobre todo las de tiempo, lugar, modo y causa, como ya ocurría en latín, parece ser una preferencia del discurso narrativo medieval ${ }^{33}$.

\section{Oraciones subordinadas temporales}

Las oraciones subordinadas temporales son las que habitualmente se sitúan en la posición preverbal. Esta preferencia viene motivada por la necesidad que tiene el historiador de encuadrar cronológicamente la narración de los acontecimientos:

E quando llego el mandado a la rreyna doña Maria de cómo el rrey don Fernando su hijo era muerto, tomo ende muy gran pesar e hizo muy gran llanto por el. (GCA, I, 10). E quando el ynfante don Juan e don Juan Nuñez lo supieron, ovieron ende muy gran placer, e pusieron su pleytesia amos; (GCA, I, 11). E quando esto vio el ynfante, [...], puso las espuelas al cauallo (GCA, XXI, 15).

El nexo más empleado en estas subordinadas temporales antepuestas es desque $e^{34}$ que, al igual que ocurre con la colocación inicial de adverbios del tipo dende, entonces y luego, tiene propiedades ilativas por su propio significado básico de secuencia temporal. Normalmente, el encadenamiento entre el discurso precedente y la información a la que el tema da paso mantiene relaciones de correferencialidad, a través de la presencia de un adverbio o de un demostrativo neutro, lo que aumenta el efecto cohesivo de las secuencias:

E desque el ynfante don Pedro supo quellos dezian esto, partió luego de allí do estaua, (GCA, III, 21). E desque don Juan Nuñez esto supo, fuese a ver luego

33. Vid. J. EldviRa González, art. cit., p. 258.

34. Para un análisis más exhaustivo, puede consultarse F. J. Herrero Ruiz de Loizaga, art. cit., p. 340 . 
con el ynfante don Joan (GCA, III, 56). E desque el ynfante don Pedro supo esto metió todos los caualleros e otras gentes que yvan con el (GCA, IV, 31). E desque esto supo el ynfante don Pedro partió de Palençia de noche y fue a tenerle el camino (GCA, V, 47). E desque esto ovieron puesto y firmado tornose el ynfante don Joan para Cuellar (GCA, VI, 34). E desque el ynfante don Joan e ellos vieron esto, enviaron a pedir por merçed a la rreyna, que era en Palençia, que llegase a Ca/rrion. (GCA, XIII, 23). E desque esto supo el ynfante don Pedro, pesole mucho (GCA, XIV, 8). E demientra que ellos estauan en esto, el ynfante don Joan y don Joan Nuñez e todos los otros que con ellos eran vinieronse para Peña Fiel [...] (GCA, VI, 16). E en tanto que el ynfante don Pedro andaua en esto, la rreyna doña Maria partió de Avila y vinose para Valladolid (GCA, VII, 28). Estando ellos en esto, acaesçio que don Joan hijo del ynfante don Manuel vino a tierra de Almaçan e de Berlanga (GCA, IX, 17). Estando en esto llegaron el obispo de Burgos y el de Salamanca (GCA, VII, 44).

A la cohesión temporal entre las oraciones del texto, viene a sumarse la correferencia espacial que también las une, materializada a través de los deícticos anafóricos ay/allí, poco proclives a la posición inicial, que hacen referencia a un lugar previamente presentado:

E otro dia partieron dende luego e vinieron su camino para Sahagund, e lleuava hasta quinientos caballeros e tres mill hombres de pie. E ante que ay llegase, lo supo el ynfante don Juan [...] (GCA, III, 24-26). E dende vinieronse para Valladolid al rrey. E este dia que ay llegaron era el plazo cumplido (GCA, XIII, 43). E desta guisa se fue hasta en Cordoua. E estando ay de morada con toda su gente, llegole mandado (GCA, XIV, 15-16). Para yr por tierra a desçercar a Gibraltar. E desque los moros supieron que el ynfante don Pedro querie yr alli, no fallaron por su pro (GCA, XIV, 20-21).

A veces aparece un pronombre que funciona simultáneamente con carácter anafórico y catafórico, aunque no suele ser lo habitual:

E estando ellos alli, el ynfante don Pedro partio de Valladolid e anduvo toda la noche e amanesçio a las puertas de Palençia; e Diego de Corral, que era dende y era su vasallo, cogiolo en la çibdad, a el y a tres caualleros que yvan con el desemejados. E desque los de la villa lo supieron que el ynfante don Pedro era alli, aquellos que eran del vando del ynfante don Joan fueronse luego de la çibdad (GCA, V, 40-42).

El encadenamiento discursivo del texto de la Gran Crónica afecta también a la unión entre los diferentes capítulos que conforman la obra. La referencia a episodios narrados anteriormente se verbaliza en oraciones subordinadas temporales antepuestas que desarrollan explícitamente los elementos constituyentes de la oración ${ }^{35}$. A diferencia de lo que ocurría con los ejemplos dentro de un mismo pasaje, las temporales que inician capítulos no suelen

35. Ibid., p. 342 . 
condensar la información mediante un pronombre demostrativo neutro. Una de la circunstancias, pues, que contribuye a la ausencia de estos demostrativos en las temporales es, pues, el paso de un capítulo a otro:

E con este rrecabdo se tornaron los mensajeros e contaron la respuesta del rrey de Granada al ynfante don Pedro (GCA, XIX, 21 [fin del capítulo]). Quando el ynfante oyo la respuesta del rrey de Granada, [...] (GCA, XX, 2 [inicio del capítulo]).

Solo se rompe esta cohesión entre capítulos cuando comienza un nuevo año del reinado de Alfonso XI, caso en el que se emplea la expresión formularia En el comienço del rreynado del noble rrey don Alonso (GCA, I, 3), En el segundo año del rreynado deste rrey don Alonso (GCA, VII, 5).

Con relativa frecuencia las estructuras temporales se van encadenando unas a otras de modo que la información circunstancial introducida en una secuencia se constituye en el punto de arranque de la frase siguiente, logrando de este modo articular un texto coherente:

E otro dia despues que lo alçaron por rrey, acordaron de lleuar a enterrar el cuerpo del rrey don Fernando su padre a la çibdad de Cordoua, que era cerca dende, [...]. E desque llegaron a Cordoua e lo enterraron, dexo ay el ynfante don Pedro a doña Costança la rreyna, muger del rrey don Fernando y madre deste rrey don Alonso, e este ynfante don Pedro fuese para Jaen para asosegar la paz con el rrey de Granada e poner rrecaudo en toda essa tierra que no quedase desanparada (GCA, I, 6-9).

Este encadenamiento discursivo de estructura informativa lineal puede resultar repetitivo al concentrarse varias estructuras subordinadas temporales precedidas por el mismo nexo:

[...] E quando el Papa Clemente vio las cartas del Ynfante don / Pedro, [...] otorgole lo que le demandaua, e enbio una carta al ynfante [...] E quando fue venida la carta del Papa, enbio su mensaje al rrey de Granada, [...] E quando el rrey de Granada vio el mensaje del Ynfante ouo ende muy gran pesar [...] (GCA, XIX, 5-13).

Las oraciones introducidas por quando, además de indicar una prelación cronológica, permiten en ocasiones que la relación temporal se traduzca en relaciones lógicas de tipo muy variado, fundamentalmente de causa-efecto pero también pueden adquirir un matiz condicional, favorecido por la presencia del subjuntivo. Estos valores aparecen normalmente en contextos de reproducción. Así, en el siguiente ejemplo puede observarse que la frase encabezada por quando queda enmarcada por la repetición de la completiva $q u e$, recurso habitual cuando se tematiza una oración subordinada dentro de este tipo de estructuras, según se puso de manifiesto anteriormente:

E dixole que toviese por bien de non querer que las hordenes fuesen metidas a tributo, lo que nunca fueron, e que escusase atal fecho como este, que no era 
seruiçio de Dios ni del rrey; e que quando el Conde esto non quisiese fazer que non podia ser que lo el Papa non sopiese (GCA, LXXVIII, 14-16).

\section{Construcciones de gerundio}

La posición inicial es la preferida para ubicar las oraciones de gerundio cuya función habitual es la de aportar información sobre marcos, contextos o situaciones en que se desarrolla la proposición principal. Estas acciones que dibujan el fondo del escenario presentan muy a menudo un valor de simultaneidad cronológica. La mayoría de los casos en los que se observa este carácter presenta el verbo estar:

E estando ellos en Leon, la rreyna doña Maria y el infante don Pedro enviaron a ellos al obispo de Çibdad Rrodrigo (GCA, V, 35). E estando ellos allí, el ynfante don Pedro partió de Valladolid (GCA, V, 40). Estando ellos en esto, acaesçio que don Joan hijo del ynfante don Manuel vino a tierra de Almaçan (GCA, IX, 17). Estando la rreyna doña Maria en Valladolid con el rrey su nieto, supo como el ynfante don Pedro avia enbiado a pedir al papa (GCA, XIV, 3). E estando ay de morada con toda su gente, llegole mandado de como los moros se ayuntauan todos para yr a çercar a Gibraltar (GCA, XIV, 16). Y estando el casamiento de esta manera, el rrey rrogo al ynfante don Felippe su tio e a doña Malgarida su muger que fuesen a Peñafiel por doña Costança (GCA, LIV, 8). Y estando el rrey en Ualladolid, nasçio don Pedro, hijo del rrey e de doña Leonor (GCA, CXVI, 26).

A veces este valor se desplaza hacia un matiz causal. La mayoría de los ejemplos en los que se percibe este valor se construye sobre la base del verbo ver:

E veyendo que la tardança del ynfante don Pedro era ya muy grande / andauan diciendo ellos que el ynfante don Pedro non dexaua de venir ay (GCA, IV, 10). El arçobispo, veyendo que non podia al fazer, pues que ella dezie que querie venir a Tordesillas, ovo de venir el ay (GCA, XXV,2). E el rrey, por esto, e otrosi veyendo la gue/rra que tenie començada con los moros, e los males e daños que le fazie don Joan hijo del ynfante don Manuel e otros en el rreyno, otorgogelo (GCA, LXXVI, 17-18). E la rreyna doña Maria, veyendo el mal e daño que las tierras del rrey rresçibian, ovo gran pesar, e adolesçio de vna dolencia de que fino. Y el su cuerpo fue enterrado en las Huelgas de Valla/dolid e Dios por su merçed le de perdonamiento e le faga eredera en el su santo rreyno, amen. (GCA, XXXVIII, 7-10).

El matiz causal de las construcciones de gerundio se manifiesta formalmente en su sustitución por un sintagma preposicional con este valor cuando media una gran distancia entre las circunstancias que sirven de marco y el verbo principal, según se observa en el siguiente ejemplo, caracterizado por una gran complejidad sintáctica en su articulación discursiva:

E el rrey, veyendo como don Joan hijo del ynfante don Manuel no queria sosegar en su servicio, e que lleuara del los dineros e no gelos fuera a seruir, e otrosi que 
le fazie gran daño en la tierra; e pensó que en quanto don Joan asi lo fiziese, no podrian los de la tierra dalle lo que avie menester para la guerra de los moros; e otrosi vio que otorgando al rrey de Granada lo que le enbiava a decir, que lo ganaua por su vasallo, e que lo tirava de ayuda de don Joan; e por esto ovo de otorgar la tregua al rrey de Granada por aquel tienpo, e rresçibiolo por vasallo (GCA, CXII, 8-12).

A diferencia de lo que ocurre con los textos alfonsíes ${ }^{36}$, las construcciones absolutas con valor de anterioridad temporal no son demasiado habituales en el corpus analizado, en el que se observa mayor abundancia de estas en el libro tercero:

E enbiados estos mensajeros, partio de Segouia (GCA, LXIV, 41). Fecha la conquista destos lugares (GCA, LXXIII, 26).

Es muy frecuente que aparezcan tras la reproducción de un discurso ajeno, lo que les confiere un carácter de estructura formularia:

Oyda la rrazon que le dixeron los de Valladolid (GCA, L, 35). Vistas las cartas e oyda la mensajeria que le dixeron de parte del rrey (GCA, LXIV, 21). Oyda esta mensajeria (GCA, LXXV, 14). Oydas las cosas que los mensajeros del Papa le dixeron (GCA, LXXXVIII, 16). Oyda la mensajeria que el Conde le enbio a decir (GCA, XCIV, 9).

En alguna ocasión no aparece el verbo de la cláusula:

E estos pleitos e posturas e firmezas entre los rreyes, el rrey de Castilla fue para la frontera, pasando por los lugares de Pastrana e de Fuente el Enzina e Almonaçir, e por tierra de Çorita, lugares de la horden de Calatraua (GCA, CIV, 30-31).

\section{Oraciones subordinadas causales}

Las subordinadas causales de los textos analizados, a diferencia de lo que ocurre con las temporales, no muestran una clara preferencia por la posición inicial. En el corpus analizado se observa que esta posición es más habitual en el libro II que en el primero. Hay que tener en cuenta a este respecto que el cronista, en su interés por delinear las pautas de comportamiento a las cuales debe ajustarse el ideal de realeza ${ }^{37}$, pretende dar

36. Con el fin de establecer un contraste entre ambos períodos, puede consultarse J. ElviRA GonzÁLEz, art. cit., p. 263.

37. Ya en el libro I se hace explícito el discurso laudatorio hacia el monarca: «E la ventura non es otra cosa sinon graçia que Dios pone en quien es la su merçed, que de otra guisa quien dize ventura es palabra perdida. E, por çierto, sepan todos aquellos que esta historia oyeren que Dios quiso dar siempre honrra en el su comienço a este rey e / graçia e ventura, por que sienpre fue onrrado e rrey venturoso sobre los rreyes que Dios hizo en su tiempo; e ansi lo pueden todos ver por la Coronica suya, do se habla de sus fechos grandes e marauillosos quel començo e que dio cauo a su honra e a su voluntad» (GCA, XXXV, 10-13). 
cuenta de los acontecimientos narrados revelando la actitud cautelosa y prudente del monarca, lo que lingüísticamente se materializa en subordinadas causales que explican las razones que motivan las diferentes acciones de Alfonso XI una vez que sale de la etapa de las tutorías ${ }^{38}$ :

E por que de luengos tienpos era acostunbrado en las casas de los rreyes de Castilla que auia almoxarifes judios, el rrey por esto, e por rruego del ynfante don Felippe su tio, tomo por almoxarife a vn judio que dezian don Juçafe de Eçija (GCA, LI, 12).

En el ejemplo anterior se observa que, tras la anteposición de la subordinada causal, se hace explícito el sujeto (el rrey) e inmediatamente se recupera mediante un sintagma preposicional la referencia a esa causal inicial (por esto) a la que se le coordina una nueva causa desarrollada proposicionalmente. Este encadenamiento de causales constituye una estructura muy habitual y pone de manifiesto una vez más el deseo del cronista por distribuir la información de manera coherente haciendo avanzar informativamente el texto sobre un soporte previamente presentado:

E por esto, e por que algunos de los que el rrey tomara para su casa vieron que los no llamaua tantas vezes ni tan afincada mente en sus fechos, sospecharon aquellos dos, don Joan e don Joan, e todas sus conpañas, de lo que ellos se rrecelaban (GCA, LIII, 8). E por esto, e otrosi porque este don Joan traya fabla con doña Sancha, [...], e otrosi por lo que le dixo el mensajero del rrey de parte del rrey, por eso vino a Berver, que era lugar suyo desde don Joan (GCA, LXII, 20-21). E el rrey, por esto, e otrosi por yr a tomar algunos castillos que estauan cerca antes que pasase el tiempo del verano, e por que el invierno venia cerca, touo por bien de ffazer lo que los moros de la villa le pedían (GCA, LXXII, 49-50). E el rrey, por esto, e otrosi veyendo la gue/rra que tenie començada con los moros, e los males e daños que le fazie don Joan hijo del ynfante don Manuel e otros en el rreyno, otorgogelo (GCA, LXXVI, 17-18). E por esto, e otrosi porque este

38. Cuando Alfonso XI sale de la etapa de las tutorías, una de las primeras medidas que toma es organizar su Consejo. Lo hace con hombres del entorno del infante don Felipe - Garcilaso de la Vega, Alvar Núñez Osorio, y Yucef de Écija como tesorero - , a quienes elige por «su saber», pese a estar al corriente de los delitos cometidos durante su minoría (cap. LI, p. 376 377). Esta característica tópica del buen consejero no ahorra los disgustos posteriores del soberano con sus funcionarios y su consecuente cambio de conducta. En lo inmediato, la elección del cuerpo consiliario trae aparejado un conflicto interno: la enemistad de los otros poderosos. Don Juan el Tuerto y don Juan Manuel se malquistan con el soberano, justamente, por no ser convocados a constituir el círculo asesor cortesano (cap. LIII, p. 379-380). La crónica se hace eco, en un gran porcentaje del relato, de las constantes desavenencias entre los magnates alejados de la Corte (a la cabeza siempre don Juan Manuel) y el soberano, terminando en muchos casos con la eliminación del rebelde, así como ocurre con el asesinato de don Juan el Tuerto, convocado por el privado en Toro con el pretexto de integrar el Consejo en la guerra contra los moros (cap. LXII, p. 393-395). Vid. María Fernanda Nussbaum, «Monarquía y consejeros en la Crónica de tres reyes: un modelo de gobierno para el reinado de Alfonso XI», e-Spania, 12, 2011. URL: [http://e-spania.revues.org/20670]. 
don Joan Ponce puso grande alboroto en el tiempo de las tutorías en / quanto el rrey estaua en Valladolid, [...], por esto, e por muchas querellas que fablo del, el rrey mandole cortar la cabeça (GCA, LXXX, 12-13).

\section{Elementos combinados en la secuencias iniciales complejas}

Con cierta frecuencia, especialmente en el libro II, se observa una acumulación de elementos con indicaciones circunstanciales que tiene como consecuencia inmediata la complicación estructural de la posición preverbal. Las secuencias iniciales que, como se ha visto, sirven para encuadrar la acción narrativa principal, pueden adoptar mayor complejidad al combinarse diferentes estructuras. Así, con el fin de aportar al lector información detallada, es frecuente una alta complejidad en las fórmulas que introducen los datos relativos a los años de reinado de Alfonso XI, a las que se añade el año primero en la era hispánica y luego en el cómputo cristocéntrico:

En el comienço del rreynado del noble rrey don Alonso, que fue el onzeno deste nombre en la casa de Castilla, que començo a rreynar en el mes de Setienbre, que fue en la era de Çesar de mil e trezientos e quarenta e siete años, quando andava el año del nasçimiento de nuestro señor Jesu Christo en mil e trezientos e nueve años, en el dia que lo alçaron y lo nombraron y lo rreçibieron por rrey e por señor, era este rrey don Alonso de edad de vn año e veynte e seys días mas (GCA, I, 3-5).

En el siguiente ejemplo se observa como toda una serie de causas antepuestas al verbo principal tienen necesariamente que ser recuperadas mediante la expresión por todas cosas:

E veyendo el rrey en como estos don Joan e don Joan eran los mas poderosos omes del su rreyno, e que le podrian fazer gran guerra e gran daño en la tierra; e demas, que en este tiempo era biuo don Alfonso hijo del ynfante don Fernando, por cuya boz ovieron grandes contrarios el rrey don Fernando su padre e el rrey don Sancho su abuelo; y el rrey aviendo rreçelo que le podría venir algund deseruiçio en la tierra por aquellos dos omnes, por quanto los via muy abibados para le hazer quanto deseruiçio podiesen, ca dizen que dixo don Joan hijo del ynfante don Joan que el cuydaua hazer mucho como fuese rrey de Leon a pesar de quien lo contradixese; asi que por todas cosas ovo el rrey su consejo con algunos de los sus consejeros (GCA, LIII, 17-20).

El sujeto, constituido en tema, puede quedar marcado por la pausa que una cláusula incidental (relativa, temporal) conlleva, al permanecer separado del verbo y del resto de las funciones actanciales. Las subordiandas temporales destacan por su extremada frecuencia en esta posición. Dentro de la continuidad de patrones historiográficos alfonsí se documenta un tipo de estructura que por su frecuencia en los textos se califica de formularia ${ }^{39}$. Se trata de

39. Vid. J. Elvira González, art. cit., p. 247. 
la anteposición de un nombre propio al que se le intercala a modo de inciso una subordinada temporal precedida de quando, seguida de un verbo emotivo:

E doña Maria, muger que fue del ynfante don Juan, quando lo supo, pesole ende mucho (GCA, XXX, 21). Don Juan Nuñez, quando oyo lo que le enbio a decir aquel cauallero, ovo ende muy gran placer, [...] (GCA, II, 2).

Además del tiempo, pueden intercalarse otros contenidos entre el tema y el verbo, como ocurre con las aposiciones que identifican a los personajes que intervienen. Esta organización secuencial supone un corte en la línea discursiva que une el tema con el predicado, al mediar entre ellos una fórmula de inciso. De ahí la frecuencia con la que aparecen sintagmas que recuperan anafóricamente el hilo narrativo mediante la repetición de una entidad previamente activada precedida habitualmente de un demostrativo:

E desque llegaron a Cordoua e lo enterraron, dexo ay el ynfante don Pedro a doña Costança la rreyna, muger del rrey don Fernando e madre deste rrey don Alonso, e este ynfante don Pedro fuese para Jaen para asosegar la paz con el rrey de Granada e poner rrecaudo en toda essa tierra que no quedase desanparada (GCA, I, 9).

La complejidad estructural de la posición inicial originaba en los textos alfonsíes algunas construcciones sintácticas en las que la colocación en posición inicial de un sintagma nominal separado del verbo de la oración principal por una o más frases apositivas podía traer como consecuencia que tal grupo quedase desvinculado del contexto gramatical subsiguiente y no desempeñase ninguna función sintáctica en la oración principal ${ }^{40}$ :

Mas vn alto omne que auie nombre Tendio, de consuno con los otros altos omnes que quisieron ser leales vasallos al rrey, sacaronle luego del monesterio, et entregaronle el señorio del rreyno (Versión Crítica de la Estoria de España, XLIX: 4-6).

Este tipo de construcción, que da lugar a problemas en la asignación de funciones sintácticas a los elementos antepuestos, no se documenta, salvo en alguna ocasión, en la crónica analizada:

E doña Maria, muger que fue del ynfante don Juan, quando lo supo, pesole ende mucho (GCA, XXX, 21).

Por el contrario, los sintagmas nominales que ocupan la posición inicial, a pesar de la intercalación entre ellos y el verbo principal de elementos parentéticos, no suelen presentar dificultades para una correcta asigna-

40. Es lo que la Retórica ha llamado anacoluto, y que sigue plenamente vivo en la oralidad y en el coloquio, donde los destacamientos pragmático-discursivos se anteponen a las formalizaciones sintácticas. Para un análisis explicativo de la presencia de estas construcciones en los textos alfonsíes, vid. J. Elvira González, art. cit., p. 247. 
ción del papel sintáctico desempeñado, hecho que puede poner de manifiesto el desarrollo de la elaboración intensiva en la tradición discursiva de las Crónicas.

\section{Conclusiones}

En el discurso informativo moderno existe una fuerte tendencia a que la posición inicial de las cláusulas que componen el texto sea ocupada habitualmente por información previamente introducida o fácilmente deducible por el contexto, lo que facilita el acceso cognitivo del destinatario. Esta disposición de la materia informativa se encuentra ya presente en las crónicas medievales, en las que la disposición de los elementos oracionales no queda determinada únicamente por las relaciones sintácticas que se establecen entre ellos, sino por la intención comunicativa del autor de jerarquizar la información que transmite con el objetivo de lograr configurar un texto coherente. En la Gran Crónica de Alfonso XI se observa que las expresiones que con más frecuencia ocupan la posición temática son aquellas que ofrecen un marco contextual para la interpretación adecuada de la acción principal pero estas difieren en función del carácter narrativo o argumentativo de los contenidos que se transmiten. Así, en los entornos de discurso reproducido, se observa una preferencia por enmarcar cláusulas de carácter circunstancial pero asociadas a discursos argumentativos a través de relaciones sintáctico-semánticas de causalidad, consecuencia, adversación, condición, concesión y finalidad. En estos contextos es habitual que se produzca el encuadramiento de una secuencia o constituyente entre la conjunción que introductora de cláusula completiva y la repetición de la misma conjunción al final del segmento que se enmarca en la posición inicial de dicha cláusula. Además, es en estos entornos de discurso reproducido donde más habitualmente aumenta la complejidad sintáctica de la posición inicial.

Por su parte, en los pasajes narrativos, que constituyen la mayor parte de la obra, las expresiones que con más frecuencia sirven de punto de arranque del mensaje son las vinculadas a la temporalidad, materializadas no solo en subordinadas temporales sino también en adverbios temporales, oraciones de gerundio, locuciones temporales y, en menor medida, estructuras absolutas. Estos contenidos temporales que se sitúan al principio recogen, a modo de encadenamiento, las referencias previamente introducidas, de forma que se logra una estructura informativa de carácter lineal en la que parte del rema de una oración anterior se constituye en el tema de la siguiente. Aun existiendo formas más breves para condensar lo anteriormente introducido (luego, dende, estonçes $\left.{ }^{41}\right)$, existe una preferencia

41. Vid. F. J. Herrero Ruiz de Loizaga, art. cit., p. 345. 
por hacer explícitas las circunstancias que enmarcan la predicación de la nueva cláusula. En estos casos, al deseo de precisión por parte del cronista se suma el mantenimiento de un molde prototípico heredero de la tradición cronística alfonsí. La temporalidad se constituye, pues, como el principal mecanismo cohesivo ${ }^{42}$ en la narración de unos hechos que trata de preservar a través de la escritura la memoria del ejercicio del poder.

42. Ibid., p. 340 . 